\title{
Krom Kaplamalı Parçalarda Termal Çevrim Analizi
}

\author{
Ali Ozan Bağrıyanık*
}

\section{$\ddot{O Z Z}$}

Araç içi ve dışında geniş kullanım alanına sahip krom kaplamalı parçalar, bulundukları konuma göre farklı dış etkilere maruz kalmaktadır. Yağmur, toz ve güneş nedeniyle parça üzerinde korozif ve termal etkiler görülmektedir. Bu çalışmada, krom kaplamalı plastik parçaların üzerinde sıcaklık nedeniyle oluşan çatlaklara neden olabilecek termal deformasyonların sonlu eleman yöntemiyle analiz edilebileceği bir yöntem geliştirilmiştir. Kaplamayı oluşturan katmanlar ayrı ayrı modellenip termal analiz yapılmışıır. Katmanların kalınlıklarının ve parça üzerindeki geometrik değişikliklerin termal yükler sonrası oluşan gerilme dağıllmına etkisi incelenmiştir.

Anahtar Kelimeler: Krom kaplama, termal analiz, sonlu elemanlar metodu, ssıl genleşme katsayısı, termal çevrim

\section{Thermal Cycle Analysis in Chromium-Plated Parts}

\begin{abstract}
Chromium Coated parts which are widely used inside and outside of a vehicle are exposed to different external conditions. Corrosive and thermal effects can be observed on the part due to rain, dust and sun. In this study, a finite element method is developed in order to anlyze the thermal deformations which may lead cracks on chromium coated parts, The layers of the coating are modelled seperately. The effects of the thickness of the layers and the geometric changes on the fracture were investigated.
\end{abstract}

Keywords: Chromium coating, thermal analyses, finite element method, thermal expansion coefficient, thermal cycle.

\footnotetext{
İletişim Yazarı

Geliş/Received : $\quad$ 27.05.2019

Kabul/Accepted : : 27.11.2019

1 TOFAŞ Türk Otomobil Fabrikası Ar-Ge Merkezi, Bursa - aliozan.bagriyanik@tofas.com.tr ORCID: 0000-0002-8512-3450
} 


\section{GÍRIŞ}

Otomotiv sektöründe artan rekabet nedeniyle müşteri ilgisini çekebilmek firmalar için hayati derecede önemli duruma gelmiştir. Müşteriler tarafindan en çok dikkat edilen ve aracın satışına direkt olarak etkisi olan parçalara, farklı boyama çeşitleri ve kaplama çeşitleri uygulanmaktadır. Yumuşak dokunuşlu yüzeyler, parlak metalik boyalar, lazer ve kumaş kaplamalar bunlara örnek olarak verilebilir [1]. Günümüzde s1kça kullanılan bir yöntem de krom kaplama uygulamasıdır.

Krom kaplamanın araçlarda kullanılmasının sebebi estetik plastik parçalar üzerinde ayna parlaklığg ve metal görünümü elde etmektir. Bu parçalar aracın içinde ve dışında kullanılabilmektedir. Bu parçalara örnek olarak iç ve dış kapı kolları, süs çıtaları, torpido üzerindeki bazı paneller, tuşlar, radyatör gizleyici ızgaralar verilebilir. Bu parçalar direkt olarak müşteri tarafından görülebildiği veya kullanılabildiği için görsel durumları araç için önemli bir performans kriteri haline gelmektedir. Araç dışında kullanılan krom kaplamalı parçaların bazıları Şekil 1'de görülebilir.

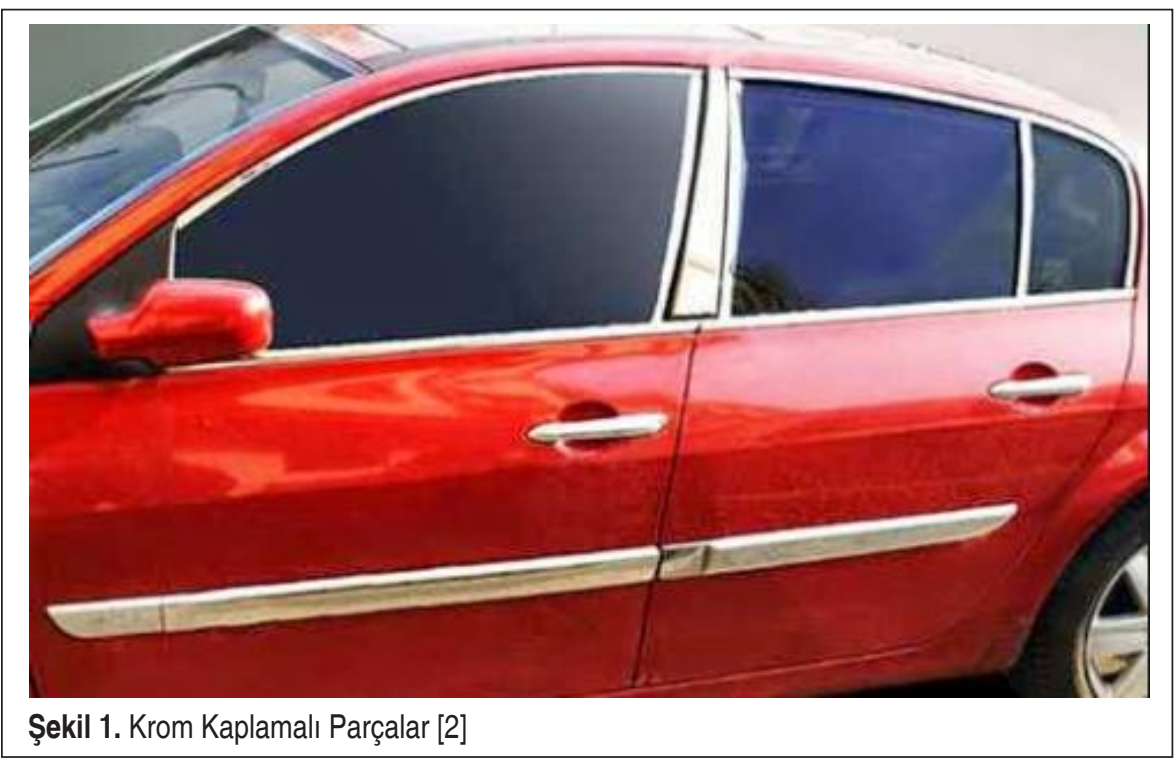

Parçalar üzerinde yaşanan yüksek sıcaklık değişimleri, düzensiz şekil değişimleri meydana getirir ve kaplama üzerinde çatlaklar oluşumuna neden olmaktadır [3]. Bu gibi durumlarda firmalar birçok test ve değişim maliyetleri ile karşı karşıya kalmaktadır. Parça üzerinde oluşan bu çatlakları tasarım aşamasında yakalayıp önlemler almak, test ve değişim maliyetlerini oldukça indirmektedir.

Çatlak oluşumuna ilişkin yapılan bir çalışmada Ploypech vd [4], asit konsantrasyonu ve kaplama sıcaklığının çatlak oluşumuna etkisini incelemişlerdir. Khodadad ve Lei [5] 
alüminyum bir yüzey üzerine yapılan krom kaplama kalınlıklarını cevap yüzey metodu ile istatistiksel olarak incelemiştir. Almotairi [6] ince ve kalın krom kaplamalı paslanmaz çelik numuneler üzerinde mekanik ve termal hasarları incelemiştir. Umesh vd [7] nikel ve krom alaşım ile sprey yöntemiyle kaplanan bir çelik levha üzerinde, 3 nokta eğme testi sonucunda oluşan gerilmeleri sonlu eleman yöntemiyle analiz etmişlerdir. Yapılan çalışmada kaplama katmanı ve çelik ayrı ayrı modellenmiştir. Kaplama kalınlığ1 arttıkça eğilme yüklerinde parçanın performansının arttığ1 görülmüştür. Logan [8] krom kaplamanın çelik üzerindeki plastik deformasyona etkisini araştıran çalışmasında, kaplamalı parçalarda kaplamasız parçalara göre çekme testinde uzama değerlerinin azaldığını ortaya koymuştur. Plastik malzeme seçimi parçanın fonksiyonuna ve plastik malzemenin krom kaplama uygunluğuna göre yapılmalıdır. ABS plastikler, polikarbon ABS alaşımlı plastikler krom kaplama için kullanılan bazı malzemelerdir.

Bu çalışmada, araç dışında kullanılan krom kaplamalı bir parçada oluşabilecek çatlak başlangıç senaryolarını sonlu elemanlar metodu ile analiz edebilmek için bir metot geliştirilmiştir. Çatlak ilerlemesi ile ilgili bir çalışma yapılmamıştır. Kaplamadaki katmanlar modellenmiş ve termal genleşme analizleri yapılarak kalıcı deformasyon oluşma durumları incelenmiştir. Bu sayede kaplama üzerinde çatlak oluşabilecek bölgelerde, tasarım aşamasında gerekli değişiklikler yapılıp, fiziksel testlerde çatlak oluşumunun önüne geçmek hedeflenmiştir.

\section{KAPLAMA ÖZELLIKLERİ VE YAPILAN FİZIKSEL TESTLER}

\subsection{Kaplama Özellikleri}

Krom kaplamalı parçalar, araç üzerinde bulundukları konum itibarı ile farklı ortam koşullarına maruz kalmaktadırlar. Örneğin, araç içi ve dışında, sıcaklık -30 ve $+80{ }^{\circ} \mathrm{C}$ arasındaki değerlere ulaşabilmektedir [9]. Aynı zamanda yağmur, kar vb. hava koşullarına maruz kalan parçalarda korozif etkiler de görülebilmektedir. Bu nedenlerden dolayı kaplama özellikleri parçanın bulunduğu konuma ve müşteri tarafından kullanımına göre FIAT malzeme normunda [10] üç farkı sınıfa ayrılmıştır. Araç üzerinde kullanılan kaplama sınıfları Tablo 1'de verilmiştir.

Tablo 1. Kaplama Tipleri [10]

\begin{tabular}{|c|l|l|}
\hline Kaplama Tipi & \multicolumn{1}{|c|}{ içerik } & Araçta Kullanım Alanı \\
\hline I & Cu X Ni Y Cr & $\begin{array}{l}\text { Direkt atmosferik etkilere maruz kalmayan ve elle kullanılma- } \\
\text { yan araç içi parçalar (çerçeveler, vb.) }\end{array}$ \\
\hline II & Cu 2X Ni 2Y Cr & $\begin{array}{l}\text { Direkt olarak atmosferik etkilere maruz kalmayıp elle kullanılan } \\
\text { parçalar (tuşlar, kapı panelleri, torpido panelleri) }\end{array}$ \\
\hline III & Cu 4X Ni 4Y Cr & Araç dışı parçalar (far çerçeveleri, kapı kolları vb.) \\
\hline
\end{tabular}


Tablo 2. Kaplama Kalınlıkları [10]

\begin{tabular}{|c|c|c|c|}
\hline \multirow{2}{*}{ Tip } & \multicolumn{3}{|c|}{ Minimum Lokal Kalınlık $(\mu \mathrm{m})$} \\
\cline { 2 - 4 } & $\mathrm{Cu}$ & $\mathrm{Ni}$ & $\mathrm{Cr}$ \\
\hline $\mathrm{I}$ & $2 \mathrm{~A}$ & $\mathrm{~A}$ & $\mathrm{~A} \times 10^{-1}$ \\
\hline II & $4 \mathrm{~A}$ & $2 \mathrm{~A}$ & $\mathrm{Ax10^{-1 }}$ \\
\hline III & $8 \mathrm{~A}$ & $4 \mathrm{~A}$ & $\mathrm{Ax10^{-1 }}$ \\
\hline
\end{tabular}

Krom kaplamalar 3 farklı katmandan oluşmaktadır. Üretim prosesinde parça farklı kimyasal havuzlara daldırılır ve sırasıyla, bakır, nikel ve krom malzemeleri ile kaplanır. Tablo 1'de belirtilen tiplere göre, her bir katmanın sahip olması gereken kalınlık değeri de değişmektedir. FIAT normlarına göre kaplama katmanlarına ait nominal kalınlık değerleri Tablo 2'de verilmiştir. Tablo incelendiğinde, araç dışında kullanılan Tip III kaplamalarda, bakır ve nikel katmanlarının diğer tiplere göre daha kalın olması gerektiği anlaşılmaktadır.

\subsection{Yapılan Testler}

Parçanın maruz kalabileceği zorlu durumlar, ardışık olarak yapılan termal ve korozyon testleri ile incelenir. Testlere başlanmadan önce katman kalınlıkların kontrol edilmesi ve parçaların yüzey uygunluğunun onaylanması gerekmektedir. Kalınlık ve yüzey kontrolü onayı alan parçalar ilk olarak termal çevrim testine girer. Termal çevrim testi, FIAT normuna [10] göre aşağıda belirtilen şekilde yapılır.

- $80 \pm 2{ }^{\circ} \mathrm{C}$ 'de sicak havaya 30 dakika maruz birakılır.

- Oda sıcaklığında 45 dakika soğumaya bırakılır.

- $-30 \pm 2{ }^{\circ} \mathrm{C}^{\prime}$ de soğuk havaya 30 dakika maruz bırakılır.

- Oda sıcaklığında 45 dakika soğumaya bırakılır.

Daha sonra alınan bu parçalar korozyon testine tabi tutulur. Burada asidik nem etkisine maruz bırakılır. Kaplama tipine göre maruz bırakılma süreleri Tablo 3 'te verilmiştir.

Tablo 3. Korozyon Testine Maruz Bırakılma Süreleri [10]

\begin{tabular}{|c|c|}
\hline Tip & Süre (s) \\
\hline I & 6 \\
\hline II & 24 \\
\hline$I I I$ & 48 \\
\hline
\end{tabular}


Bu testler sonucunda parça üzerinde gözle kontrol yapılıp çatlaklar ve korozyon etkileri gözlemlenir. Krom kaplanmış yüzeydeki yapısal bozukluklar, çatlaklar, kirletici nesneler parçanın görüntüsünü ve performansını olumsuz yönde etkiler ve test sonucu negatif olarak belirlenir.

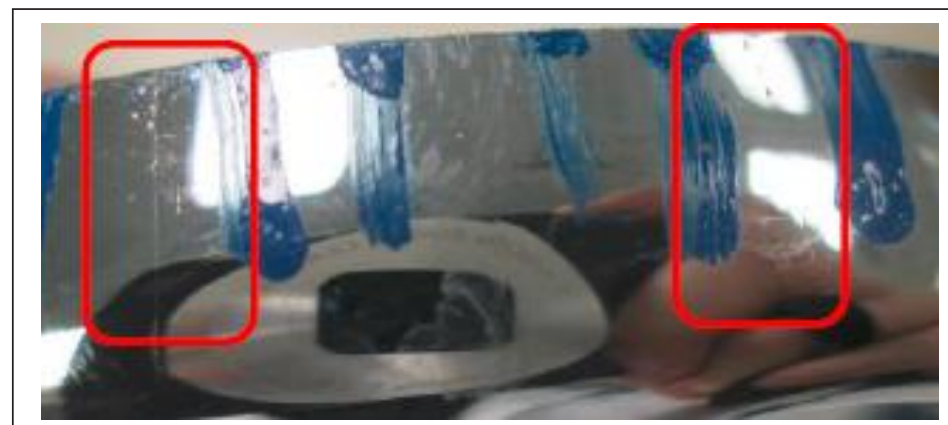

Şekil 2. Krom Kaplanmış Yüzeyde Test Sonrası Gözlenen Çatlaklar

Test sonucunda oluşan çatlaklara ait bir örnek Şekil 2'de gösterilmiştir. Fiziksel teste giren parçanın üst kısmında kaplama çatlağı tespit edilmiştir. Çalışmanın devamında bu parça ele alınmış ve kaplama üzerinde hasar oluşma durumlarının incelenmesi için bir sanal analiz metodu geliştirilmiştir.

\section{SONLU ELEMAN ANALIZLERİ}

\subsection{Sonlu Eleman Modeli ve Kaplama Tanımlanması}

Sonlu eleman modeli iki farklı kısımdan oluşmaktadır. Kaplanan plastik parça 3 Boyutlu katı (tetra) elemanlar ile modellenmiştir. Ortalama eleman boyutu $1 \mathrm{~mm}$ olarak kullanılmıştır. Modellenen tetra elemanlar Şekil 3 'te görülebilir.

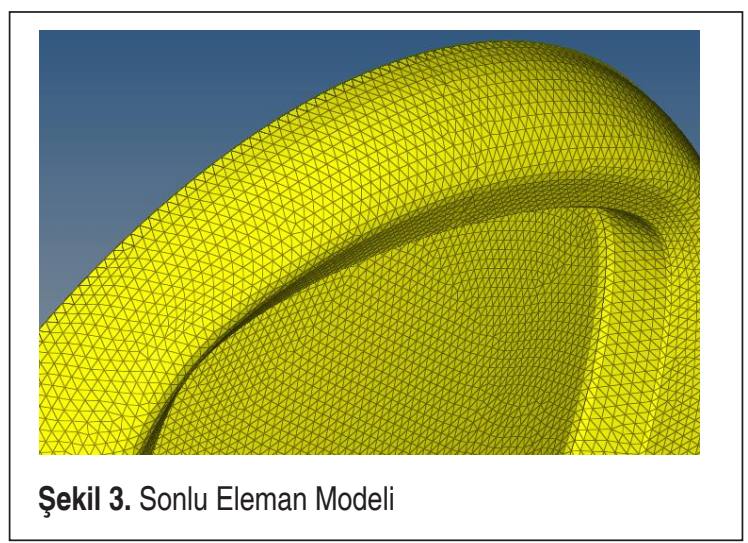




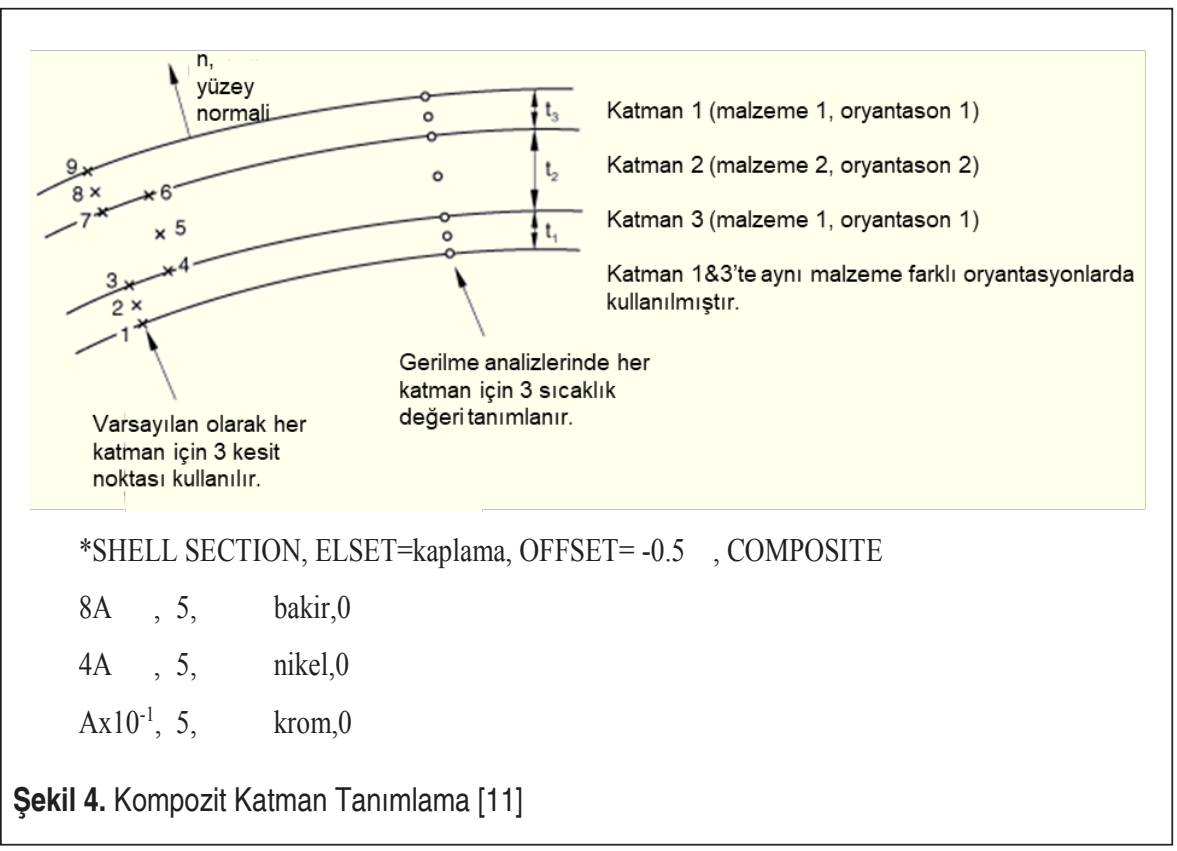

Kaplama kendi içerisinde üç farklı malzeme ve kalınlıktan oluşmaktadır. Kaplama katmanları tek tek üç boyutlu katı olarak modellendiğinde kalınlıkları mikron seviyesinde olduğu için çok ince kalınlıkta elemanla ortaya çıkmış ve çözümün güvenli olması için yeterli eleman kriterleri sağlanamamıştır. Bu nedenle kaplama iki boyutlu kabuk elemanlar ile modellenmiştir. Kaplama, plastik parça modeline ait elamanların dış yüzeyleri kullanılarak oluşturulmuştur. Krom kaplama ve plastik parçanın dış yüzeyine ait dügümler ortaktır.

Geleneksel yöntemde her bir kabuk modellenen parçaya bit kalınlık ve malzeme girdisi tanımlanmaktadır. Kaplama durumunda ise kabuk olarak oluşturulan kaplama modeline farklı kalınlık ve malzeme bilgilerinin atanması gerektiği için farklı bir metot ihtiyacı ortaya çıkmıştır. Yapılan araştırmalarda kabuk elemanlara farklı kalınlık ve malzeme katmanları atanmasına imkân kılan kompozit malzeme yaklaşımı, kaplama tanımlanmasında kullanılmıştır. Abaqus yazılımı içerisindeki, kompozit katman özelliği sayesinde kaplamayı tanımlayan üç farklı malzeme katmanı ve bu katmanlara ait kalınlıklar modele tanımlanmıştır. Kompozit katman özelliğinin şematik anlatımı Şekil 4'te görülebilir.

Geleneksek kabuk modellerinde, kalınlık orta yüzeyden (midsurface) eleman normalinde, pozitif ve negatif yönlerde yarım birim olarak tanımlanmaktadır. Çalışmada kullanılan yöntemde, öteleme (offset) özelliği kullanılarak katman kalınlığı eleman normalinde tek yönde tanımlanmıştır. Sonlu elaman modeline ait bir kesitteki kalınlık 

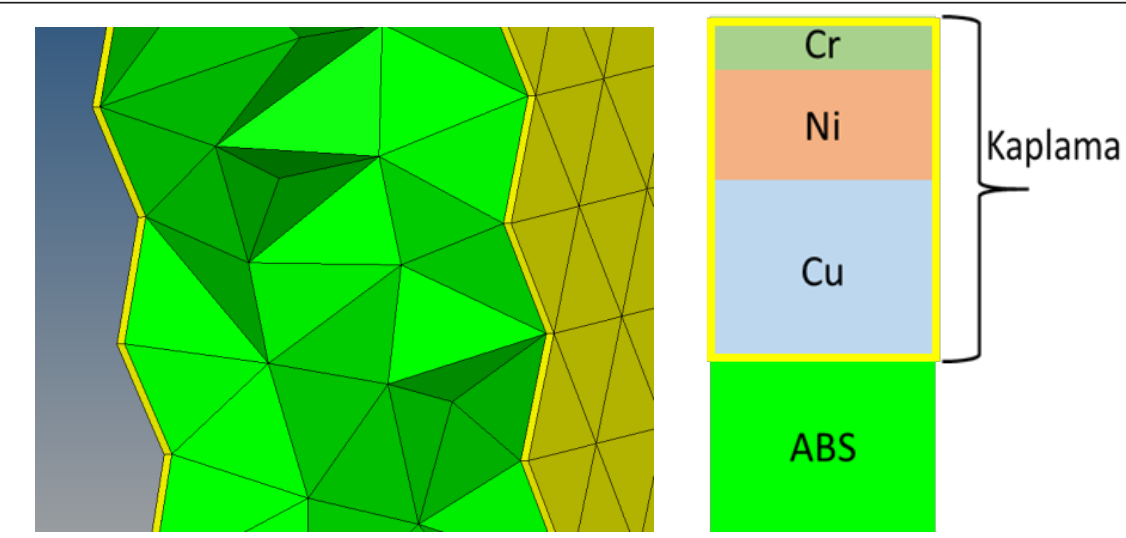

Şekil 5. Sonlu Eleman Modeli Kesit Görünümü

durumu Şekil 5'te verilmiştir. Yeşil olarak belirtilen kısım ABS malzemeyi göstermektedir. Kaplama ise sarı olarak belirtilip, kaplama detayı açıklanmıştır.

Sonlu eleman analizinde kullanılması için fiziksel parça üzerinden kaplama kalınlığı ölçümü yapılmıştır. Fakat parça üzerindeki yüzeylerin çok küçük ve düzgün olmaması nedeniyle tüm bölgelerde kalınlık ölçümü yapılamamıştır. Ölçüm yapılan noktalarda da farklılıklar tespit edilmiştir. Tüm bu nedenlerden dolayı fiziksel parçadaki kaplama kalınları modele aktarılamamıştır ve Tablo 2'de belirtilen Tip III kaplama için sağlanması gereken minimum değerler tüm modele tanımlanmıştır.

\subsection{Malzeme Özellikleri}

Yapılan sonlu elaman analizlerinde elastoplastik malzeme modeli kullanılmıştır. Malzemelere ait elastisite modülüne, poisson oranına, plastik bölgeye ait gerilme-uzama eğrilerine ve termal analiz için ısıl genleşme katsayılarına ihtiyaç duyulmuştur. Yapılan literatür araştırmaları sonucu krom, bakır ve nikele ait malzeme özellikleri elde edilmiştir. Analizlerde kullanılan gerilme-uzama eğrileri Şekil 6 ve Şekil 7'de verilmiştir.

Plastik ABS için elastoplastik malzeme özellikleri ve ısıl genleşme katsayısı tedarikçiden alınarak kullanılmıştır. Analizde kullanılan tüm malzemelerin ısıl genleşme katsayıları arasındaki ilişki Tablo 4’te verilmiştir.

\subsection{Sınır Koşulları ve Termal Çevrim}

Fiziksel test sırasında parça araç üzerinde değil tekil olarak firına koyulup test edilmektedir. Bu sebeple analizlerde parça tekil olarak incelenmiştir. Parçanın firına yerleştirilme durumu göz önünde bulundurularak parçanın firın yüzeyine değecek düğüm 


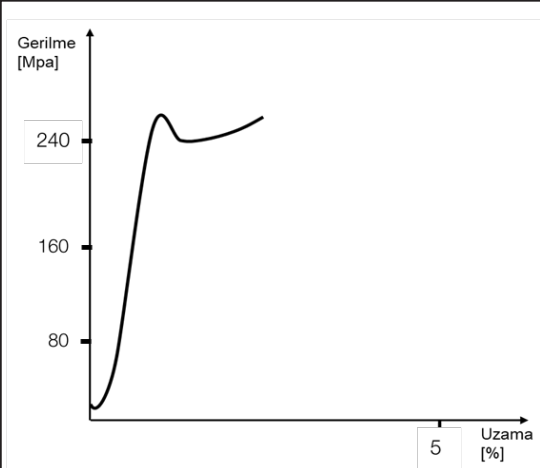

a)

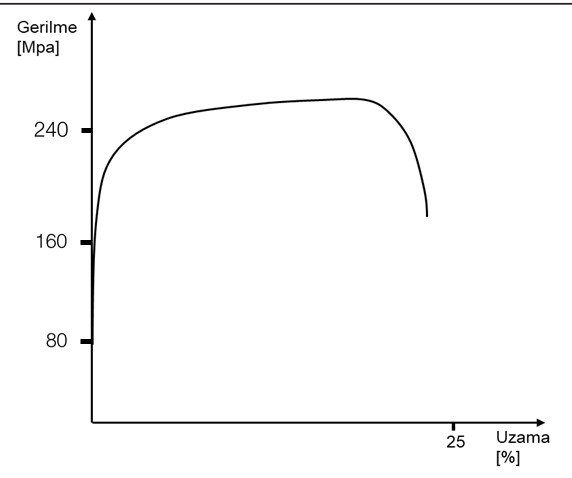

b)

Şekil 6. Krom İçin $25^{\circ} \mathrm{C}$ a) ve $300^{\circ} \mathrm{C}$, b)'de Gerilme-Uzama Eğrisi [12]

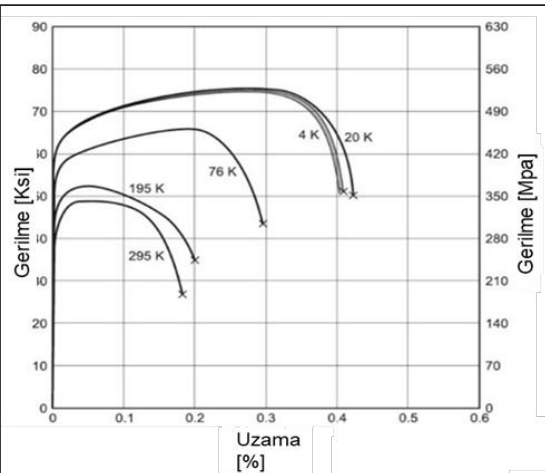

a)

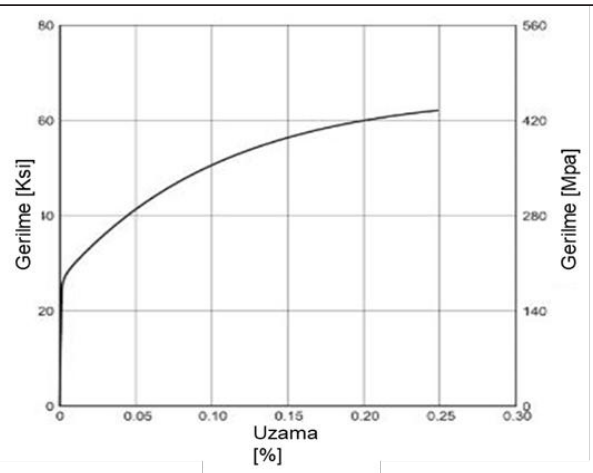

b)

Şekil 7. Bakır a) ve Nikel b) İçin Çeşitli Sıcaklıklarda Gerilme-Uzama Eğrisi [13-14]

Tablo 4. Termal Genleşme Katsayıları

\begin{tabular}{|c|c|}
\hline MALZEME & TERMALGENLEŞME KATSAYISI $\left(10^{-6} \mathrm{~m} /(\mathrm{m} \mathrm{K})\right)$ \\
\hline ABS & $9.4 \mathrm{X}$ \\
\hline KROM & $\mathrm{X}$ \\
\hline BAKIR & $1.2 \mathrm{X}$ \\
\hline NIKEL & $1.6 \mathrm{X}$ \\
\hline
\end{tabular}


noktalarının tüm yönlerdeki öteleme ve dönme harekeleri kısıtlanmıştır.

Fiziksel testte parçalar, her bir sıcaklıkta belirli bir süre bekletilmektedir. Fakat malzemelere ait sürünme bilgileri elde edilemediği için analizlerde bekletilme durumu incelenememiştir. Bölüm 2.2 de belirtilen sıcaklık değişismleri, sonlu eleman analizinde dört ayrı termal statik yükleme adımında sırasıyla uygulanmıştır. Fiziksel test ve analizde uygulanan termal statik yükleme koşulu Şekil 8'de verilmiştir.

\subsection{Termal Çevrim Analizleri}

Analizlerde, termal yüklemeler sonucu oluşan gerilme dağılımı incelenerek hasar oluşabilecek bölgelerin belirlenmesi amaçlanmıştır. Parça üzerinde kalınlık ölçümü yapılamadığı için incelme senaryoları analiz edilmiştir. Buna ek olarak, sonlu eleman modelinde geometrik değişiklikler uygulanarak maksimum gerilme değerinin değişimi araştırılmıştır.

\subsubsection{Nominal Kalınlık Analizleri}

Normda belirtilen kalınlık bilgileri ile yapılan analizde sadece krom katmanına ait gerilme ve gerinim dağılımı sonuçları Şekil 9a'da görülmektedir. Hesaplanan maksimum gerilme değeri A MPa seviyesindedir ve malzemenin akma gerilme değerinin altında olduğu için kaplama üzerinde kalıcı deformasyon oluşmamıştır.

Gerilme dağılımı incelendiğinde, gerilme seviyesi arttığında düşey yönde kalıcı deformasyon oluşacağı ve kaplama üzerinde fiziksel teste benzer hasar oluşacağı öngörülmüştür. Bu nedenle Şekil 2'de görülen çatlak oluşma bölgesinde kalınlık incelmesi senaryoları uygulanmıştır.

\subsubsection{Kaplama Kalınlıklarının İncelmesi Durumları}

Fiziksel testlerde oluşan hasar durumlarının en önemli sebeplerinden biri kaplamanın

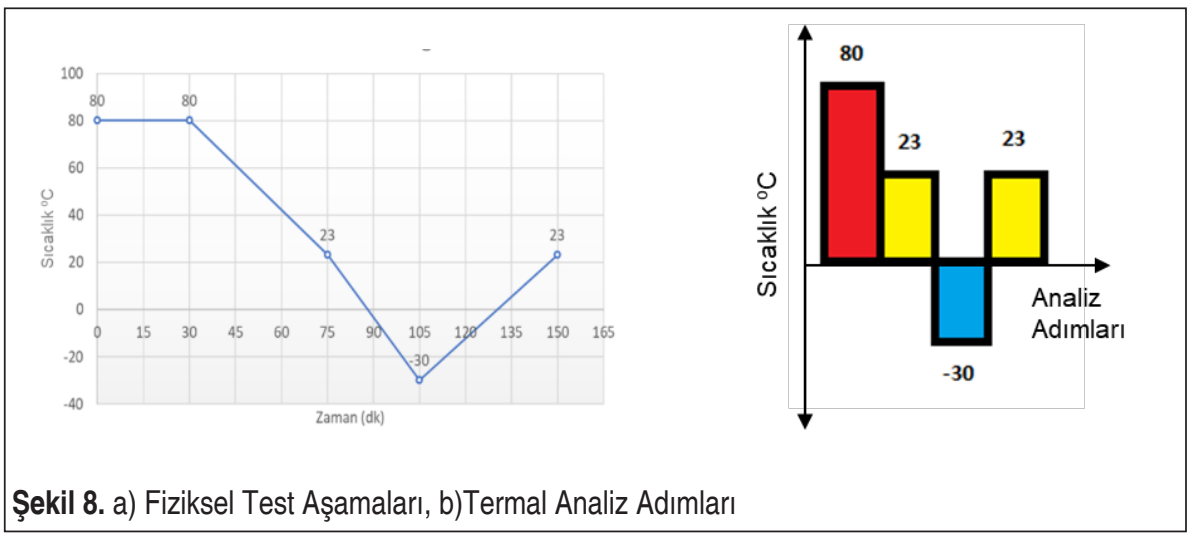




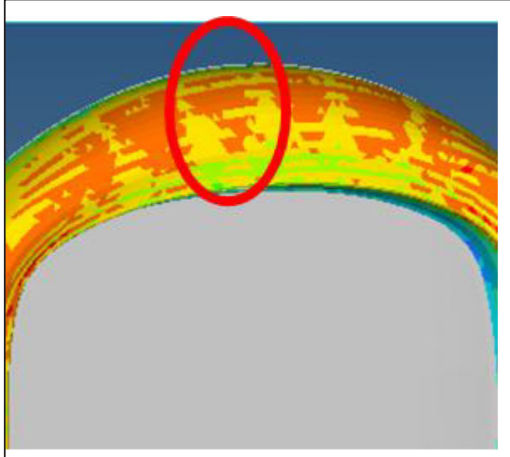

a)

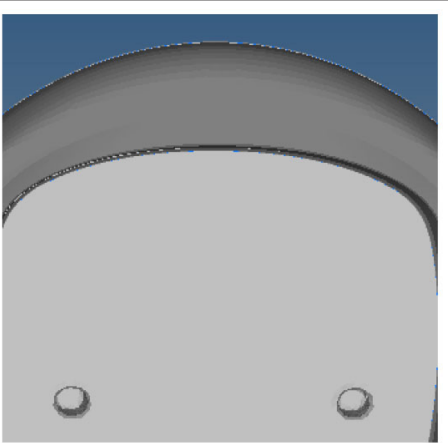

b)

Şekil 9. a) Nominal Kalınlık Durumunda Oluşan Gerilme Dağılımı ve b) Kalıcı Deformasyon

kalınlığının çatlayan bölgelerde nominal kalınlık değerlerini sağlamamasıdır. Testlerde karşılaşılan birçok farklı kaplama çatlağında yapılan incelemelerde, kaplama kalınlığının çatlama görülen yüzeylerde olması gereken değerlerin altında olduğu belirlenmiştir. Bu sebeple, fiziksel testte çatlama oluşan bölgede oluşabilecek kalınlık incelmesi senaryosu incelenmiştir. Bunun yanı sıra her bir katmanın kalınlığının tekil etkisi de incelenmiştir.

\subsubsection{1 Üst Bölgede Kalınlık Incelmesi Durumu}

Fiziksel testler sonrasında, parçanın üst kısmında çatlak ile karşılaşılmıştır. Bölgenin eğri ve küçük olması nedeniyle kaplama katmanlarının kalınlıkları ölçülememiştir. Bu nedenle, kaplama katman kalınlıklarının \%20 inceldiği varsayımı yapılarak analizler tekrar edilmiştir. Şekil 10'de kalınlık inceltmesi yapılan bölge sarı renkte gösterilmiştir.

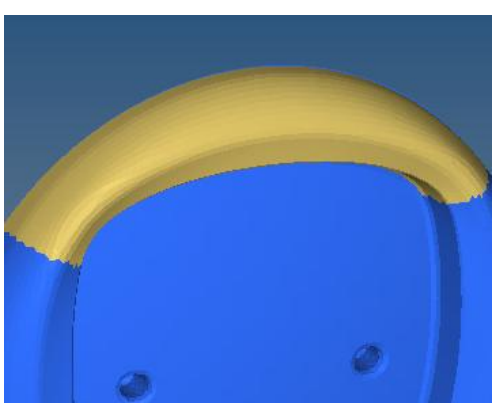

Şekil 10. Üst Bölge İçin Kalınlık İncelmesi Durumu 


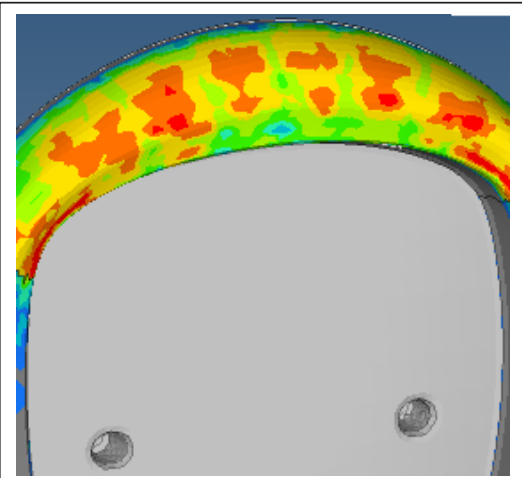

a)

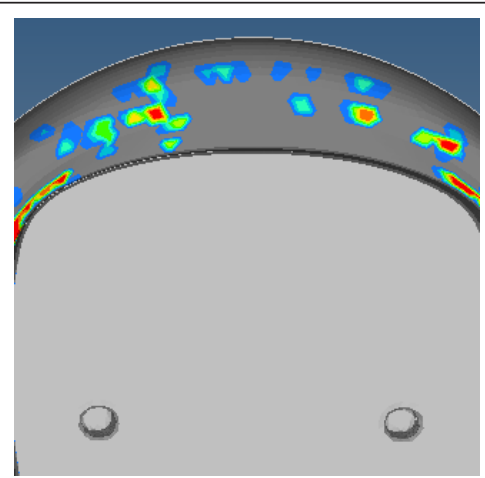

b)

Şekil 11. a) Kalınlık Incelmesi Durumunda Oluşan Gerilme Dağılımı, b) Kalıcı Deformasyon

Şekil 11'de temel durum ile üst bölgede kalınlık incelmesi olan durum birlikte verilmiştir. Parça üzerinde oluşan maksimum gerilme değeri \% $\%$ artış göstererek 1,07A MPa olarak hesaplanmıştır. Ayrıca gerilme değeri akma mukavemetinden yüksek olduğu için parça üzerinde oluşan kalıcı gerinim değeri \%B olarak hesaplanmıştır. Gerilme ve gerinim sonuçları incelendiğinde, fiziksel testte oluşan çatlaklara benzer gerilme dağılımı görülmektedir.

\subsubsection{Bakır, Nikel ve Krom Kalınlıklarının Analizde Etkisi}

Bakır, nikel ve krom kalınlıklarının, plastik deformasyon değerlerinde hangi ölçüde etkili olduğunun araştırılması için üç katmanda da ayrı ayrı \%20 kalınlık incelmesi olduğu varsayılarak üç tane analiz yapılmıştır. Her bir katmanın plastik deformasyona etkisi yüzde olarak Şekil 12'de verilmiştir.

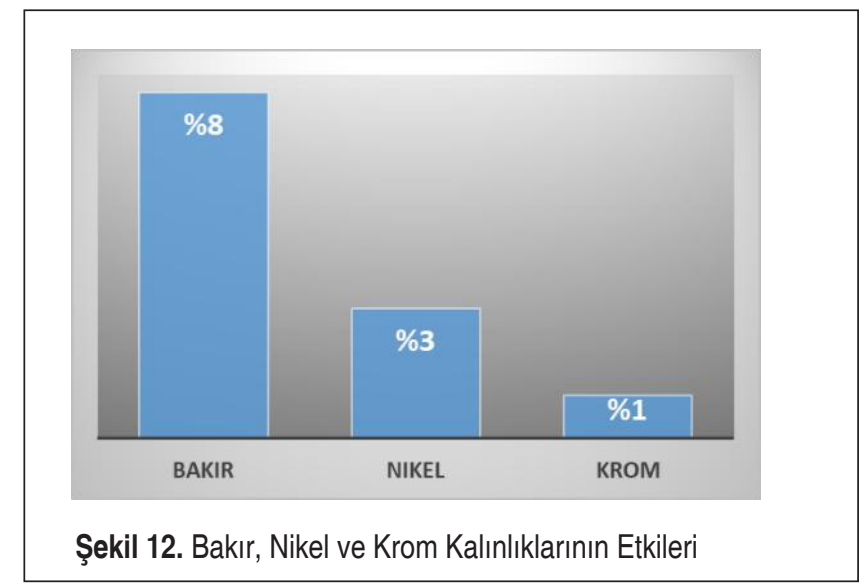


Katman kalınlıklarının etkileri incelendiğinde bakır katmanının kalıcı deformasyonda en etkili parametre olduğu görülmektedir. Sonuçlara göre termal çatlakların giderilmesinde malzeme katmanlarındaki kalınlık artışına gidilmesi söz konusu olduğunda, bakır kaplama katmanının kalınlığının artırılması nikel ve krom malzemelerinde kaplama kalınlığının artırılmasına göre daha etkili sonuçlar verecektir.

\subsubsection{Geometrik Modifikasyon Durumları}

Kaplama kalınlıklarının etkilerinden sonra parça üzerindeki geometrik etkiler incelenmiştir. Ele alınan parçanın arka yüzeyinde bulunan kiriş yapısının gerilme dağılımına etkisini incelemek için kirişlerden bazıları silinerek analizler tekrarlanmıştır. Kirişlerin mevcut ve yeni durumları Şekil 13’te görülebilir.

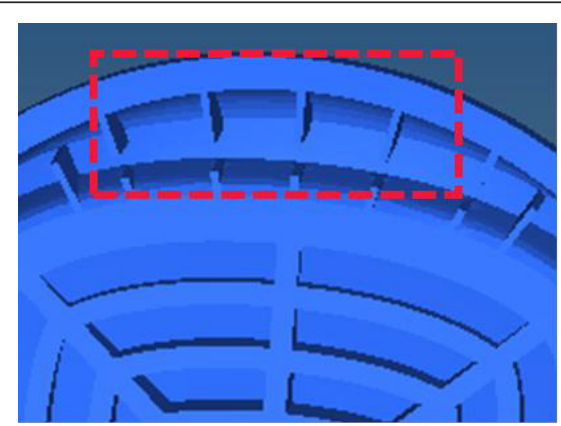

a)

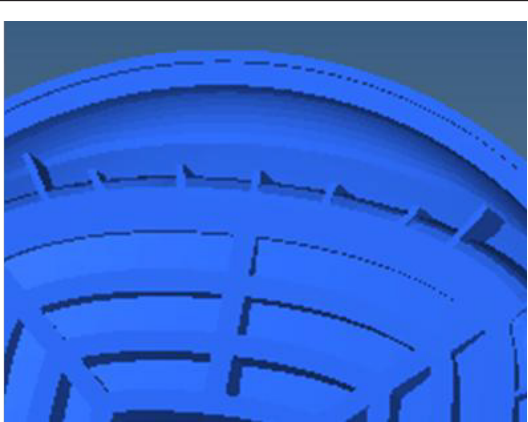

b)

Şekil 13. a) Mevcut Kirişli Tasarım, b) Kirişlerin Kaldırıldığı Durum

Kirişlerin kaldırıldığı durumda hesaplanan maksimum gerilme değeri 0.86A Mpa seviyesindedir. Şekil 9a'daki mevcut duruma ait gerilme haritası ile karşılaştırıldığında, gösterilen bölgede gerilme seviyesinin düştüğü ve daha yumuşak bir gerilme dağılı-

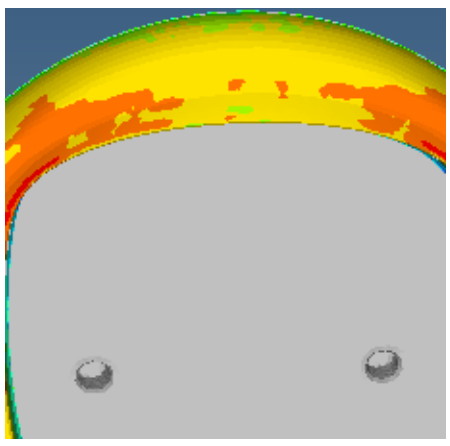

Şekil 14. Üst Bölgedeki Kirişlerin Kaldırıması Durumu İçin Analiz Sonucu 
mı oluştuğu görülmektedir. Ayrıca maksimum gerilme, akma mukavemeti değerinin altında olduğu için kalıcı deformasyon oluşmamıştır. Analiz sonuçları Şekil 14'da verilmiştir.

\section{SONUÇLAR}

Bu çalışmada, krom kaplamalı parçalarda termal çatlak oluşumunu analiz eden bir metot geliştirilmiştir. Metotta her bir katman ayrı ayrı modellenip termal genleşme analizleri gerçekleştirilmiştir. Yüksek gerilme bölgeleri incelenip, kalıcı gerinim değerlerine bakılarak çatlak oluşma durumu incelenmiştir. Yapılan analizlerde, sonuçları etkileyen önemli faktörlerden birisinin üretim sırasında kaplamada oluşan kalınlık incelmeleri olduğu görülmüştür. Kaplama kalınlığında oluşan \%20 incelmenin, maksimum gerilme değerini \%7 oranında arttırdığı hesaplanmıştır. Dolayısıyla üretim sırasında kaplamada oluşan kalınlık incelmelerinin, kaplama üzerinde hasar oluşmasında büyük bir etkiye sahip olduğu görülmüştür.

Kaplama kalınlığında bakır, nikel ve krom malzeme kalınlıklarının etkisi incelendiğinde en etkili olan malzemenin \%8 oranıyla bakır olduğu görülmüştür. Buna göre parça üzerinde görülen hasara müdahale edildiğinde bakır kalınlığı arttırılarak en iyi sonuç elde edilebileceği ortaya çıkmıştır.

Yapılan analizler sonucu plastik deformasyonlarda etkili olan bir diğer parametrenin parçanın arka kısmında yer alan kirişlerin olduğu ortaya çıkmıştır. Kirişlerin kaldırılması durumları için analiz yapıldığında hesaplanan maksimum gerilmede \%13,5 seviyelerinde azalma görülmüştür. Bu sayede tasarım aşamasında yapılacak analizler sonucu plastik deformasyon görülen bölgelerde, benzer geometrik değişiklikler yapılarak tasarım iyileştirme çalışmaları yapılması olanağı sağlanmıştır.

\section{TEŞEKKÜR}

Bu çalışma TÜBITAK 1501 TEYDEB 3141073 numaralı projenin finansal desteği ile tamamlanmıştır.

\section{KAYNAKÇA}

1. Anonim, 2000. https://www.omsaline.com, (2015).

2. Streitberger, H.-J \& Dössel, K.-F. 2008. "Automotive Paints and Coatings," 2nd Edition, p. 335

3. Aniekan, I., Kelly, O.E., Abdulsamad, G. 2017. "Engineering Material Selection for Automotive Exhaust Systems Using CES Software,” International Journal of Engineering Technologies-IJET, Vol. 3, No.2

4. Ploypech, Suwat \& Metzner, Martin \& Beatriz dos Santos, Claudia \& Jearanaisilawong, Petch \& Boonyongmaneerat, Yuttanant. (2019). Effects of Crack Density on Wettability 
and Mechanical Properties of Hard Chrome Coatings. Transactions of the Indian Institute of Metals. 72. 10.1007/s12666-018-01553-4.

5. E. Khodadad, M. K. Lei 2014. Crack-bridging Bonding in Trivalent Chromium Composite Coatings on Pure Aluminum Using Carbon Nanotubes for Wear Resistance, International Journal of Electrochemical Science, vol.9, p. $2882-2895$

6. Almotairi, A. 2016. "Mechnical and Thermal Damage of Hard Chromium Coatings pn 416 Stainless Steel," Master of Applied Science, Dalhousie University, Halifax

7. Umesh,F., Mallikarjun, B., Dr. Ramesh, C.S. 2015. "Analysis of Bending Stresses On Coating Materials by Experimental and FE Method," International Journal of Mechanical and Industrial Technology, Vol. 2, Issue 2, p. 41-50

8. Logan, H. 1951. "Effect of Chromium Plating on the Plastic Deformation of SAE 4130 Steel", Journal of Research of the National Bureau of Standards, vol. 46, No.6, p. 472479

9. Johnson, R \& L. Evans, John \& Jacobsen, Peter \& Thompson, J.R.R. \& Christopher, Mark. 2004. "The Changing Automotive Environment: High-Temperature Electronics" IEEE Transactions on Electronics Packaging Manufacturing, vol. 27, No. 3

10. FIAT Norm 2009, Chromium plated parts

11. Abaqus, Analysis User's Guide v6.13.

12. Heieck, J. 1997. Mechanical Properties of High-Purity Chromium,Institute for Advanced Materials, Italy

13. Reed, R.P. and Mikesel, R.P. 1967. Low Temperature Mechanical Properties of Copper and Selected Copper Alloys, Institute for Materials Research, National Bureau of Standarts Monograpgh 101, p. 35

14. ASM International 2002, Atlas of Stress-Strain Curves, 2nd Edition, p. 631 